\title{
Beitrag zur Kenntnis der Cholesterinesterverfettung.
}

Von -

Franz Valentin, Assistenten des Institutes.

(Aus dem Institute für medizinische Chemie der Tierärztlichen Hochschule in Wien.)

(Der Redaktion zugegangen am 28. August 1916.)

$\mathrm{Zu}$ der von Aschoff ${ }^{1}$ ) angeschnittenen Frage der Cholesterinesterverfettung liefere ich im folgenden einen kleinen Beitrag. Im November 1915 übersandte mir Dr. med. vet. R. Harabath, Stadtobertierarzt in Wien, Fettgewebe von einem Schwein, in welchem sich zahlreiche braune, umschriebene Stellen, offenbar nekrotische Herde, befanden. Er teilte mir dazu folgendes mit:

- Die Ihnen übersendeten nekrotischen Herde fand ich im Fettgewebe der Bauchdecke bei vollkommen ausgemästeten Schweinen ungarischer Provenienz und zwar unter dem Wandblatte des Bauchfelles in Form von höckrigen, 1-2 cm dicken, bis handflächengroßen Platten. Die Konsistenz war derb, fast knorpelhart, auf dem Durchschnitte war das Gewebe mattglänzend oder glanzlos, trübe, von gelblich weißer bis grau-. gelber Farbe. Die nekrotischen Herde ließen sich ziemlich leicht von dem normalen Fettgewebe loslösen. Herde von gleicher Beschaffenheit in Form von Knoten waren auch im Gekrösfette anzutreffen.s

Bei der mikroskopischen Untersuchung dieser Stellen fanden sich in das Fettgewebe zahlreiche Kryställchen von zweierlei Typus eingelagert. Die eine Gruppe der Krystalle zeigte die Gestalt feiner, oft büschelförmig gruppierter Krystallnadeln, der andere Typus zeigte die Form kurzer, dicker Prismen. Im polarisierten Lichte untersucht, erwiesen sich die kurzen, dicken Prismen als doppeltbrechend, nicht aber die feinen Krystallnadeln. Nach diesem Befunde lag die Vermutung nahe, $\mathrm{daB}$ die feinen Krystallnadeln aus Fettsäuren, die kurzen, dicken

1) Zur Frage der Cholesterinverfettung beim Menschen. Unna-Festschrift, Bd. I, 1910.

Hoppe-Seyler's Zeitschrift f. physiol. Chemie. XCVIII. 
Prismen aus Cholesterinestern bestehen. Diese Vermutung war nunmehr durch die chemische Untersuchung zu erhärten.

$\mathrm{Zu}$ diesem $\mathrm{Z}$ wecke wurden die nekrotischen Herde durch Herauspräparieren aus dem Fettgewebe tunlichst vom normalen Fettgewebe isoliert, sie wurden in kleinere Stücke gescbnitten und im Extraktionsapparate mit Äther extrahiert.

Von der Ätherlösung wurde der Äther abdestilliert und der Destillationsrückstand im Wasserbade im W'asserstoffstrom getrocknet. Zum Nachweise der Cholesterinester wurde der Abdampfrückstand der Behandlung mit Aceton unterworfen, welche Panzer zum Nachweise der Cholesterinester in der großen weißen Niere und andern krankhaft veränderten Organen verwendet hatte ${ }^{1}$ ). Durch dementsprechendes wiederholtes Umkrystallisieren des Destillationsrückstandes aus heißem Aceton wurde eine ziemlich reichliche Menge eines farblosen, krystallinischen Produktes erhalten. Seine Menge betrug schätzungsweise ein Fünftel des Ausgangsmateriales. Die Krystalle wurden nach dem Vorgehen Panzers in Benzollösung mit Natrium und Alkohol verseift und aus dem Verseifungsprodukte das Cholesterin von den Fettsäuren getrennt. Die letzteren zeigten die für Fettsäuren charakteristischen Reaktionen. Das gewonnene Cholesterin mehrmals zunächst aus Eisessig, später aus Alkohol umkrystallisiert, schmolz bei $144^{\circ} \mathrm{C}$. (korr.) und gab die für Cholesterin charakteristischen Reaktionen.

Der Nachweis, daß die feinen Krystallnadeln aus Fettsäuren bestehen, wurde auf indirektem Wege versucht dadurch, daß in üblicher Weise die Säurezahl des Destillationsrückstandes bestimmt wurde. Sie ergab sich mit 3,30 , also beträchtlich höher als die von normalem, frischem Schweinefett (nach Benedikt-Ulzer 0,5)²).

Der Vollständigkeit halber wurde aus dem Fette der nekrotischen Herde noch die Verseifungszahl, die Jodzahl und der Cholesteringehalt bestimmt. Die Verseifungszahl, in üb-

1) Diese Zeitschrift, Bd. 54, S. 240.

2) Benedikt-Ulzer, Anal. der Fette und Wachsarten, \&. Aufl, S. 849. 
licher Weise ermittelt, ergab sich mit 147,51. Daß diese Verseifungszahl bedeutend niedriger liegt, als sie bei normalem Schweinefett gefunden wird, erklärt sich ungezwungen aus der relativ großen Menge von Cholesterinestern. Die Jodzahl, nach v. Hübl bestimmt, war 43,6 .

Die Menge des Cholesterins betrug, nach der Windausschen Digitoninmethode bestimmt, 10,30\% (2,2456 g Fett lieferten $0,9515 \mathrm{~g}$ Digitonincholesterid). Berechnet man aus dieser Cholesterinmenge die Jodmenge, welche daran gebunden wird, so bleibt als Jodzahl des cholesterinfreien Fettes 41,0 , eine Jodzahl, welche erheblich niedriger liegt als die Jodzahl für normales Schweinefett.

Einen kleinen Beitrag zur Kenntnis der Genese dieser Cholesterinesterverfettung glaube ich durch die Resultate der Untersuchung einer zweiten Probe eines pathologisch-anatomisch ähnlich veränderten $F$ ettgewebes vom Schweine liefern zu können. Dieses Objekt wurde mir von dem Professor derFleischhygiene der tierärztlichen Hochschule in Wien, Herrn Professor Dr. A. Postolka, freundlichst zur Verfügung gestellt. Es war ihm als ein bei der Marktkontrolle konfisziertes Fettgewebe (Speckfilz) zugegangen. Von dem Speckfilze zeigte die äußerste Lage in einer Dicke von $1-1^{1 / 2} \mathrm{~cm}$ keine Veränderungen. Daran schloB sich, scharf abgegrenzt, eine zweite Schichte, welche rötlich bis rötlichgrau verfärbt und mit zahlreichen, teils streifenförmigen, teils punktförmigen Flecken durchsetzt war. Im Mittelpunkte jedes Flecken konnte mit der Lupe eine punktförmige Blutung wahrgenommen werden. Diese Veränderung nahm nach innen, also gegen die Muskeln hin, an Intensität zu, die Farbe des Fettgewebes ging allmählich mehr in grau über und war in den den Muskeln anliegenden Schichten geradezu grau.

Diese Veränderungen sollen nach Angabe des Tierarztes, welcher die Konfiskation vorgenommen hatte, erst nach der Schlachtung eingetreten sein. Diese Angabe dürfte wohl darauf zurückzuführen sein, daß die Farbstoffe durch Veränderungen, die sie an der Luft erlitten hatten, erst deutlich sichtbar geworden sind. Bei der mikroskopischen Unter- 
suchung konnten nur ganz vereinzelte Krystalle von Prismenform gefunden werden. Dagegen fanden sich etwas mehr, aber nicht so reichlich wie in dem erst beschriebenen Objekte Krystalldrusen in Form stacheliger Kugeln, bestehend aus nadelförmigen Krystallen. Viele dieser Drusen zeigten in der Mitte einen dunklen Kern. Die vereinzelten prismatischen Krystalle erwiesen sich im polarisierten Lichte doppeltbrechend. Ebenso fanden sich in den stacheligen Kugeln doppeltbrechende Teile, bald mehr, bald weniger. Jedenfalls war die Menge der doppeltbrechenden Substanz im Vergleiche zu der Menge, welche sich in dem oben heschriebenen. Fette befand, sehr gering.

In analoger Weise wie dort wurde auch hier versucht, durch wiederholtes Umkrystallisieren aus heißem Aceton Cholesterinester darzustellen. Diese Arbeit führte offenbar darum, weil die Menge der Cholesterinester zu gering war, zu keinem Resultate. Zeigte doch auch das Fett selbst sowie die durch wiederholtes Umkrystallisieren aus heißem Aceton mit Cholesterin angereicherten Fraktionen nur recht schwache Cholestolreaktionen und ebenso schwache Reaktionen nach Salkowski.

In üblicher Weise ermittelt ergaben sich:

$\begin{array}{lc}\text { Säurezahl } & 1,40 \\ \text { Verseifungszahl } & 193,76 \\ \text { Jodzahl des Fettes } & 39,9 \\ \text { Jodzahl der Fettsäuren } & 44,1 \\ \text { Acetylzahl der Fettsäuren } & 24,49 \\ \text { Unverseifbares } & 0,65 .\end{array}$

Auch aus diesen Zahlen, zumal da die Verseifungszahl zwar an der unteren Grenze, aber doch noch innerhalb jener Zahlen fällt, die normalem Schweinefett entsprechen, da ferner die Menge des unverseifbaren Rückstandes nur etwa doppelt so groß ist, als normalem Schweinefett zukommt $(0,23$ nach Benedikt-Ulzer, S. 848), ergibt sich gleichfalls, daß die Menge des vorhandenen Cholesterins und damit die Menge der Cholesterinester nur recht gering gewesen sein konnte. Dagegen stimmt die gegenüber normalem Schweinefett erhöhte Säurezahl mit 
der Ausscheidung freier Fettsäuren in den zu Krystalldrusen gruppierten Nadeln überein.

Überlegt man sich, wie etwa diese Fettsäuren entstanden sein könnten, so hat man zunächst an die. Tätigkeit eines fettspaltenden Fermentes, welches aus vorhandenem Fette die Fettsäuren freigemacht hat, zu denken. In diesem Sinne untersuchte ich das Fett auf fettspaltende Fermente. Nachdem in dem pathologisch-anatomischen Institute auf bakteriologischem -Wege nachgewiesen worden war, daß Bakterien hier nicht im Spiele waren, schnitt ich aus der Mitte eines großen Stückes Fettgewebes etwa $100 \mathrm{~g}$ heraus, verrieb es mit destilliertem Wasser und stellte es in den Eiskasten. Nach 24 Stunden wurde filtriert, $20 \mathrm{ccm}$ des schwach rötlich gefärbten Filtrates mit $12 \mathrm{ccm}$ einer Emulsion von Tributyrin versetzt und in den Brutkasten gestellt zugleich mit einer Kontrollprobe, bestehend aus $12 \mathrm{ccm}$ Tributyrin-Emulsion und $20 \mathrm{ccm}$ destilliertem Wasser. Nach einer halben Stunde wurden beide Proben nach Zusatz von Phenolphthalein mit n/2-Barytwasser neutralisiert. Die auf Ferment zu prüfende Probe verbrauchte hierzu 1,1 ccm, die Kontrollprobe nur 0,1 ccm Barytwasser. Nachdem beide neutralisierte Proben eine weitere halbe Stunde im Brutkasten gestanden waren, war die Kontrollflüssigkeit neutral geblieben, während die Fermentprobe saure Reaktion angenommen hatte und neuerdings $1,0 \mathrm{ccm}$ Barytwasser zur Neutralisation brauchte. Damit ist die Anwesenheit eines fettspaltenden Fermentes nachgewiesen.

Es scheint demnach, als ob eine fermentative Fettspaltung mit Ausscheidung freier Fettsäuren das erste Stadium des Prozesses darstellen würde und in einem zweiten Stadium erst die Einlagerung von Cholesterin, vielleicht die Umwandlung der freigewordenen Fettsäuren in Cholesterinester (doppeltbrechende Substanz) vor sich gehen würde. 